\title{
A FORMAÇÃO CONTINUADA EM SERVIÇO
}

Fernando Casadei Salles

Universidade Católica Dom Bosco, Brasil

O tema escolhido desta intervenção é o da formação continuada em serviço dos professores.

Destaquei alguns pontos a partir da experiência obtida com o desenvolvimento de um projeto de pesquisa de formação continuada em serviço, em uma escola estadual de Campo Grande, envolvendo professores da Universidade Católica Dom Bosco e da Escola Estadual Rui Barbosa.

O objetivo do referido projeto de pesquisa consiste em articular em um único processo as dimensões da prática docente com a formação continuada dos professores em serviço. Partíamos da crítica, no momento da sua proposição inicial, de que a forma mais freqüente de como as propostas de formação continuada se desenvolviam, através de cursos de suplência e ou de atualização dos conteúdos de ensino, se mostravam pouco eficientes para a melhoria da prática docente. Assim sendo, a pesquisa se dispunha, a partir desse ponto, rediscutir a concepção de formação continuada enfatizando prioritariamente a reflexão sobre a prática docente. O que significava deixar de priorizar a suplência ou atualização dos saberes escolares, definidos externamente a escola, para destacar a reflexão individual e compartilhada das práticas educativas vividas pelos docentes.

Tratava-se, em outras palavras, de opormos ao tradicional modelo de formação continuada, outro, baseado nos padrões de racionalidade prática impostos de dentro para fora da escola: a educação continuada em serviço.

Esperava-se com esse encaminhamento que os docentes da escola "investigados" produzissem, com base em seus saberes e a partir de suas práticas, um modelo próprio de formação continuada. A idéia era de que os docentes, ao refletirem sobre as suas próprias práticas, se apropriassem dos canais de diálogo entre a realidade vivida e interpretada, ampliando suas respectivas possibilidades de compreensão objetiva dos mecanismos e conhecimentos sobre a identidade profissional docente.

Isso significa dizer que, ao invés de reproduzirmos os modelos de formação continuada, baseados no paradigma do saber antes do fazer, observássemos esses modelos de um ponto de vista oposto: do universo da prática dos próprios professores "investigados". Entretanto, a experiência da realização do projeto de pesquisa mostrou que a valorização da prática como ambiente formativo não é, por si só, suficiente para resolver o problema da formação continuada dos professores. Há inúmeros outros fatores, desde escolares até extra-escolares que interferem sobre esse processo. O que nos leva a crer que 0 processo não pode ser pensado exclusivamente a partir de qualquer uma das suas partes, mas senão de todas elas ao mesmo tempo. Assim como o desenvolvimento profissional não deve ser pensado desvinculado do desenvolvimento da escola e da sociedade, a formação inicial e a formação continuada não devem ser pensadas separadamente. Elas têm de ser imaginadas, ao mesmo tempo, como partes independentes e integradas da mesma unidade de ação, o processo de formação de professores. 
Assim sendo, consideramos como indispensável para o início de qualquer discussão sobre a formação de professor, obtermos um mínimo de consenso sobre o significado dos diferentes momentos que compõem o seu desenvolvimento.

Para isso, selecionamos da pesquisa algumas questões para servirem de referência à discussão das políticas de formação de professores em serviço. Com a ressalva de, por se encontrarem, ainda, em estágio de discussão, devem servir mais a problematização do tema, do que para a sua definição.

De acordo com as pretensões limitadas da presente intervenção, foram quatro as questões escolhidas para servirem de entrada na discussão: 1. a generalidade da noção de formação continuada; 2 . formação inicial e continuada; 3 . formação continuada e formação continuada em serviço e 4. a prática docente e a formação continuada em serviço.

\section{A GENERALIDADE DA NOÇÃO DE FORMAÇÃO CONTINUADA.}

A primeira questão que conviria destacar sobre a noção de educação continuada é da forma genérica com o que ela é caracterizada; ou seja, por continuada vem se consagrando a idéia de uma educação vinculada ao cumprimento de uma tarefa infinita, em permanente mutação e, portanto, sem possibilidade de ser definitivamente realizada. Tomando a acepção de contínua, a educação continuada pode ser entendida como uma espécie de tautologia, porque, sendo um processo permanente de formação, ela encontra sempre em si mesma a sua finalidade. Essa constatação acarreta conseqüências bastante problemáticas, como, por exemplo, a incorporação do mesmo nível de tensão tautológica para se definir o profissional da educação. Assim como a noção de educação continuada se vincula à realização de uma tarefa interminável e centralizada em si mesma, também a profissão docente estaria voltada para si própria, e às voltas com problemas que não excederiam os limites dos interesses pedagógicos, ou mesmo corporativos, em um permanente estado de aprendizagem. Pode-se concluir daí que essa indefinição de finalidades poderia se estender, igualmente, à etapa inicial do processo de formação de professores, não havendo entre esses dois momentos formativos - o inicial e o continuado - diferenças conceituais significativas que os distinguissem entre si: ambos fariam parte de um único momento de formação, confundindo-se suas finalidades, objetivos e procedimentos. Da falta de uma caracterização mais objetiva da noção de educação continuada, ela se confunde com qualquer ação de treinamento, atualização, aperfeiçoamento, e tantas outras designações genéricas.

Em vista disso, pode-se afirmar que não é a polissemia da noção de educação continuada a questão problemática; o problema é a indefinição da noção que, dada sua abrangência, ao mesmo tempo em que significa tudo, é incapaz de determinar com segurança a natureza do seu objeto. Trata-se, então, de delimitar a noção, para que, sem negar a idéia generosa da educação permanente de todo ser humano inerente pela condição de ser inconcluso possamos distinguir o momento da formação inicial do outro momento que o segue, que é o da formação continuada nos seus dois sentidos: a) o da formação continuada; b) o da formação continuada em serviço. Ou seja, quando termina um momento e quando começa o outro?

\section{FORMAÇÃO INICIAL E CONTINUADA}

É preciso esclarecer a verdadeira natureza das relações entre os processos de formação inicial e continuada. Por estas relações pode-se perceber que entre os referidos processos existe o mesmo tipo de 
tensão que encontramos entre o crescimento e a procriação do ser vivo, ou seja, o indivíduo só pode procriar depois que seu organismo está formado. E o organismo precisa estar formado de uma certa maneira, senão, ele deixa de concretizar o ato da procriação.

No processo de formação de professor, a relação não é diferente; só se torna professor depois de se formar e essa formação depende de determinados requisitos indispensáveis para iniciar-se na profissão. Assim, a formação de um profissional não é um processo indefinido -o limite é dado no momento em que recebe um certificado de habilitação para o exercício da profissão docente. A formação inicial estaria, pois, diretamente relacionada, sobretudo, com a aquisição de determinadas habilidades, mínimas e indispensáveis, de acordo com as regras existentes. Por isso é que o futuro professor se concentra nessa fase com as demandas próprias da sua condição de estudante. Esse período é marcado pela ênfase na certificação de habilidades. $O$ aluno trabalha nela como se ela fosse sinônima da sua habilitação. Pensa-se exclusivamente de um ponto de vista acadêmico, de áreas, currículos, disciplinas, etc. Não the ocorre em nenhum momento nessa fase imaginar a sua formação, também como um produto do seu desenvolvimento profissional. É como se na prática, se tratasse de duas lógicas incomunicáveis entre si: uma preocupada com a aquisição de determinados saberes escolares, só possíveis de serem adquiridos por via escolar, e a outra preocupada com a obtenção de competências sócio-profissionais, exclusivamente obtidas mediante o exercício prático da profissão.

Desta feita, pode-se dizer que o primeiro problema complexo da formação dos professores diz respeito ao caráter lógico-dissociativo entre o ambiente escolar onde o aluno se habilita para a profissão e a escola em que ele trabalha como professor, onde ele efetivamente realiza o seu desenvolvimento profissional. Assim sendo, falarmos de formação do professor no seu sentido continuado quer seja ela em serviço ou não, significa antes de qualquer coisa falarmos do caráter lógico-associativo que essa prática precisa assumir frente aos problemas da teoria e da prática envolvidas no processo de formação do professor.

Talvez aqui seja interessante distinguir a questão da racionalidade técnica da racionalidade prática, para simplesmente não cairmos no maniqueísmo disto ou daquilo. Da prioridade da racionalidade técnica sobre a racionalidade prática, ou vice-versa, da racionalidade prática sobre a racionalidade técnica.

Exatamente nesse ponto emerge a questão de fundo da discussão sobre a formação continuada de professor: de que ponto de vista metodológica deve-se continuar o processo de formação do professor? Por meio da extensão, da reciclagem, da atualização dos conhecimentos obtidos na formação inicial, ou da prática docente? Mantemos o modelo cuja característica marcante é se realizar, quase sempre, como ação planejada de fora para dentro da escola? Ou invertemos a situação e trazemos o modelo de formação dos professores para o interior da escola, mais precisamente, para a prática docente?

A tendência hoje fortemente questionada, segundo Canário (1997) é colocar em questão qualquer solução baseada na perspectiva cumulativa da aquisição de conhecimentos, segundo a qual as insuficiências da formação inicial, conjugada com a obsolescência desses conhecimentos sirvam de justificativa para processos formativos estruturados pela noção de "reciclagem". Em seu lugar têm-se proposto, segundo Canário (1997:4): "uma forte valorização dos saberes adquiridos por via experiencial e, portanto, da atribuição de um papel central ao sujeito que aprende (em vez de o atribuir à figura do formador)". Assim, a tendência atual consiste em focalizar a atenção no potencial formador e transformador 
dos saberes adquiridos na experiência do cotidiano da prática docente, colocando em segundo plano qualquer noção de formação continuada destinada a atualizar ou suprir lacunas diagnosticadas na formação inicial dos professores. Essa idéia fica ainda mais assumida em Pimenta quando afirma: "O...profissional não pode constituir seu saber-fazer, senão a partir de seu próprio fazer. Não é senão sobre essa base que o saber, enquanto elaboração teórica, se constitui” (1999:26).

Apesar de concordar com a idéia da prática como critério da verdade proposta por Garrido, é preciso, no entanto, destacar o limite dessa afirmação no sentido de que a prática se mantenha apenas como critério e não se confunda com a própria verdade. Senão, ao privilegiarmos a prática docente como o lócus preferencial de formação da identidade profissional do professor, não venhamos excluir ou reduzir indevidamente o espaço de outras instâncias da formação dos professores. É necessário compreendermos o caráter complementar de cada momento do processo de formação dos professores para que o campo da prática não acabe se tornando o único domínio da formação dos professores. Em outras palavras, é como se fosse possível substituirmos simplesmente uma forma de racionalidade por outra; a racionalidade técnica pela racionalidade prática. Elegermos a escola ou o fazer-docente como o campo por excelência da formação dos professores, não significa tomá-la, no entanto, como o espaço exclusivo da "verdadeira" (e por que não única?) educação continuada.

Assim como não há por que rejeitarmos o princípio de que os professores se formam, por excelência, no contexto de suas experiências empírico-profissionais, não há também porque negarmos a formação desses profissionais em outros contextos, amplificando, ou mesmo aprimorando, suas experiências intra-escolares. Ao nosso ver, negar que os professores se formam além das suas experiências empírico-profissionais significa desculturar e, sobretudo despolitizar o tema da formação dos professores. Só para destacarmos o que talvez se possa considerar como dos mais importantes espaços de formação docente, além, evidentemente, da universidade, lembramos que os professores se formam também nas lutas democráticas e sindicais, na vida familiar, nos momentos de lazer e de fruição estética e em tantos outros que, como se pode perceber, excedem a experiência profissional restrita ao ambiente escolar.

Não é por que as nossas conviç̧ões teóricas de análise discordam dos modelos de racionalidade técnica empregados, via de regra, na formação de professores, ou discordam do sentido burocrático dado ao processo de certificação das habilidades escolares obtidas na formação inicial, que vamos desmerecer a necessidade para o desenvolvimento profissional docente de uma sólida formação inicial e na continuidade de uma renovação, extensão e atualização permanente dessa formação. Se assim fosse, não faria sentido as críticas de aligeiramento da formação inicial que caracterizam a atual política de formação de professores e tampouco as reivindicações de políticas que, de tempos em tempos, possibilitam aos professores manterem-se atualizados diante das diferentes condições de trabalho permanentemente colocadas nas suas práticas docentes, especialmente, quanto à constante introdução de novos saberes escolares.

Independentemente da maneira como as estratégias de formação continuada, inspiradas nos modelos da racionalidade técnica, são vistas e comparadas com as de formação realizadas em serviço, inspiradas nos modelos da racionalidade prática, elas não podem ser consideradas, a priori, descartáveis ou sem função; é preciso que sejam consideradas distintas. Partem de pressupostos teóricos e metodológicos distintos, mas não são irreconciliáveis, tendo em vista, principalmente, o diagnóstico quase unânime em relação à precariedade da formação inicial dos professores do país. O que implica uma estratégia de política 
de formação continuada fortemente voltada para a superação dessa deficiência. Senão é como se estivéssemos tentando continuar uma coisa que nem bem começou, a formação inicial do professor, ou que se começou, começou aligeirada e precariamente.

\section{FORMAÇÃO CONTINUADA E FORMAÇÃO CONTINUADA EM SERVIÇO}

Como vimos salientando, existem, aparentemente, duas formas de encararmos o problema da continuidade da formação dos professores. Uma é encará-la como extensão e complementação da formação inicial, ao longo da vida profissional do docente, e outra como "reflexão da reflexão da prática" como salienta Garrido (2000:5), apoiando-se nas teorias do profissional reflexivo de D. A. Schon. A primeira traduz-se por práticas "de formação fortemente escolarizadas, segundo um processo cumulativo de saberes e uma lógica de adaptação à mudança", enquanto a segunda, parte "do pressuposto que qualquer saber fazer tem de partir, obrigatoriamente, da sua própria prática docente" (CANÁRIO apud MARIN, 2000:67 ). Convicções essas que Nóvoa (2000) ratifica ao afirmar: "(...) é no espaço concreto de cada escola, em torno de problemas pedagógicos ou educativos reais, que se desenvolve a verdadeira formação do professor".

Como já vimos argumentando, apesar dessas formas serem congruentes e complementares quanto ao objetivo de formação continuada dos professores, são inegáveis as diferenças existentes entre elas, que vão desde a maneira de conceber as relações sujeito-objeto, a concepção do processo de ensinar e aprender, no papel social da profissão docente até as políticas que embasam as reformas educacionais.

Nas estratégias de educação continuada em serviço, os professores constituem-se em sujeitos do próprio processo de conhecimento e nas que são baseadas no paradigma da racionalidade técnica, o sujeito é o professor "ensinante", constituindo-se o professor "aprendente" em objeto da ação, espécie de depositário do saber. A maneira como as duas formas de educação continuada tratam o conhecimento também as torna distintas entre si. Enquanto a primeira parte da ação para a teoria, a segunda, inversamente, parte da teoria para a ação. Outra diferença significativa é que aquela mais centrada no espaço escolar acaba oferecendo ao professor plena autonomia, decorrência natural da condição de sujeito do próprio conhecimento. Já com a outra estratégia, a ação depende de fatores ou recursos externos e estranhos ao professor e até mesmo à própria escola. Por fim, mais uma diferença, mas não a última: enquanto a formação continuada baseada no saber antes do fazer, orientada pela racionalidade técnica, tem como preocupação primordial a aquisição de competências escolares que habilitam os professores ao exercício da profissão, a formação continuada em serviço diz respeito à valorização da prática docente como a única possibilidade de êxito do professor aplicar criativamente a racionalidade técnica obtida no processo de aquisição de competências escolares.

Essas diferenças, no entanto, não podem ser apontadas como expressão de um processo de ruptura epistemológica entre os modelos baseados na racionalidade técnica e na racionalidade prática. Só talvez coubesse falar em ruptura epistemológica, caso a posição de um ou outro dos modelos se mostrasse impermeável à prática do pensamento reflexivo. O que não é o caso, aprende-se com a prática como se aprende com a teoria e da mesma maneira, isto é, se refletindo criticamente sobre a experiência quer seja ela de natureza teórica ou prática. Ninguém aprende com a teoria senão refletindo criticamente sobre ela, assim como ninguém aprende com a prática senão refletindo criticamente sobre ela. 
As insuficiências técnicas da formação inicial dos professores do ensino básico são exemplos evidentes da necessidade de mantermos ativas as políticas de formação continuada baseadas na extensão, reciclagem ou atualização da formação inicial. Só para se ter noção superficial sobre as dificuldades na área, segundo dados estatísticos do MEC/INEP, Censo Escolar 1998, dos 2.045 .922 docentes, nos níveis de ensino de educação infantil, fundamental de $1^{\underline{a}}$ à $4^{\mathrm{a}}$, fundamental de $5^{\underline{a}}$ à $8^{\underline{a}}$ e ensino médio, 1.000 .071 não possuíam titulação superior ao ensino médio completo.

Tabela 1

Funções docentes por nível de ensino e grau de formação - Brasil/1998

\begin{tabular}{|c|c|c|c|c|c|c|}
\hline Nível de Ensino & Total & $\begin{array}{l}\text { Fundamental } \\
\text { incompleto }\end{array}$ & $\begin{array}{l}\text { Fundamental } \\
\text { completo }\end{array}$ & $\begin{array}{l}\text { Médio com- } \\
\text { pleto }\end{array}$ & $\begin{array}{l}\text { Superior } \\
\text { completo }\end{array}$ & Sem superior \\
\hline Total & 2.045 .922 & 58.669 & 73.213 & 868.969 & 1.045 .071 & 1.000 .941 \\
\hline Educação Infantil & 219.593 & 13.474 & 15.984 & 146.205 & 43.930 & 175.663 \\
\hline Fundamental $1^{\mathrm{a}}$ à $4^{\mathrm{a}}$ & 798.947 & 44.335 & 50.641 & 531.256 & 172.715 & 626.322 \\
\hline Fundamental $5^{\mathrm{a}}$ à $8^{\mathrm{a}}$ & 661.508 & 712 & 5.913 & 153.258 & 501.625 & 159.883 \\
\hline Ensino Médio & 365.874 & 148 & 675 & 38.250 & 326.801 & 39.073 \\
\hline
\end{tabular}

Fonte: INEP/MEC - Censo Escolar 98

Nota: $O$ mesmo docente pode atuar em mais de um nível de ensino.

A partir do que foi apresentado não é difícil concluir o quanto a nossa crítica, em geral, em relação à formação continuada voltada para a reciclagem, reatualização, ou complementação da formação inicial, cuja função consiste em restringir as conseqüências negativas desencadeadas pelo desenvolvimento desse processo, subestima os padrões de formação inicial, ainda baixos dos nossos professores. Não há, portanto, porque se opor a uma ação que tenha por finalidade melhorar a qualificação técnica dos professores; significa não compreender o caráter contínuo e complementar da sua ação em relação aos outros momentos da formação dos professores.

Neste momento, consideramos delimitados os campos de atuação de cada uma das estratégias de formação de professores: a inicial, a continuada e a continuada em serviço.

Cada uma delas cumpre o seu papel específico, assistindo ao docente em situações diferentes e em fases distintas de sua trajetória profissional. Podemos reafirmar, portanto, que educação inicial, educação continuada e a educação continuada em serviço, são todas partes indivisíveis e insubstituíveis de uma mesma coisa: a formação do professor.

\section{A PRÁTICA DOCENTE E A FORMAÇÃO CONTINUADA EM SERVIÇO}

A prática docente e a formação continuada em serviço devem ser consideradas em relação aos diferentes aspectos da prática educativa. Tanto uma como outra são indissociáveis das políticas culturais que as condicionam, bem como da definição de uma carreira mais profissional. O corolário imediato dessa afirmação é que nenhuma prática educativa se justifica fora do seu contexto político e ou social.

Como diz Canário, uma visão simultaneamente diacrônica e contextualizada do processo de formação profissional e da construção de uma identidade remete para uma concepção da aprendizagem, encarada como um processo interno ao sujeito, em que as diferentes e parcelares aquisições se combinam num sistema harmonioso, a partir de uma atribuição de sentido (1997:4).

Quer isso dizer que a prática docente e a formação continuada em serviço só se justificam como parte de um processo inacabado de permanente elaboração e reelaboração, pelo sujeito, de um sentido mais amplo do seu processo de formação profissional. 
Posição coincidente com o ponto de vista da Associação Nacional pela Formação dos Professores da Educação (ANFOPE) quando relaciona a formação continuada com a formação profissional e o aprimoramento do trabalho pedagógico. Para a ANFOPE,

a formação continuada trata da continuidade da formação profissional, proporcionando novas reflexões sobre a ação profissional e novos meios para desenvolver e aprimorar o trabalho pedagógico; um processo de construção permanente do conhecimento e desenvolvimento profissional, a partir da formação inicial e vista como uma proposta mais ampla, de hominização, na qual o homem integral, omnilateral, produzindo-se a si mesmo, também se produz em interação com o coletivo (2000:22-23)

Ao sustentar a formação continuada como uma dimensão do trabalho de profissionalização docente e conseqüentemente do trabalho pedagógico, a ANFOPE desenvolve a compreensão da formação do professor como resultado de uma ampla articulação entre os diversos espaços que vão desde a formação inicial e continuada até espaços político-social-culturais extra-escolares.

\section{CONSIDERAÇÕES FINAIS}

Como vimos analisando, a natureza do trabalho educativo de formação do professor não pode ser feito em uma base binária: disto ou daquilo, como alguns autores parecem sugerir quando afirmam que "a lógica da racionalidade técnica opõe-se sempre ao desenvolvimento de uma práxis reflexiva"(NOVOA, 1995:27). Ou então, quando argumentam a racionalidade técnica simplesmente "como uma prática derivada da filosofia positivista" (SHÖN, :15) selecionando "cientificamente" os meios técnicos mais apropriados para propósitos específicos. Por essas afirmações estaríamos obrigados a reconhecer a supremacia da prática sobre a teoria. A primeira seria, no atual contexto, prioritária em relação à segunda que seria secundária, reservada apenas a uns poucos intelectuais dedicados a grandes reflexões teóricas, os "filósofos profissionais do conhecimento". Sem desconsiderar de forma alguma a importância da prática é preciso, no entanto, ressaltar a importância da teoria não só para a reflexão sobre novas possibilidades do conhecimento como para a análise da própria prática. Sem uma formação teórica sólida fica difícil ao educador fazer qualquer análise histórica para entender a profissão docente no contexto das relações sociais vigentes, além de definir o seu papel no desenvolvimento social. Com o risco de sua prática reduzirse a um simples praticismo, Frigotto chama a atenção para o significado epistemológico dessa tendência de atribuir a prática à essência lógica do processo formativo do professor. No plano da construção do conhecimento, poderíamos acrescentar, diz Frigotto, "a perda da perspectiva teórica e epistemológica tende a reduzir a formação e a prática do educador a uma dimensão puramente técnica ou didática" (1996:390).

Assim como é impossível se conceber uma prática sem uma teoria é igualmente inconcebível pensarmos o inverso. Não existe nenhuma formação profissional docente que possa ser concebida a partir de qualquer dos seus aspectos isolados, da prática versus teoria; da teoria versus a prática; da formação inicial versus formação continuada e da formação continuada versus a formação inicial.

Isto posto, concluímos com quatro pontos para a reflexão:

- a primeira é a de que a educação continuada em serviço constitui uma atividade fundamental da formação do professor; mas não constitui a única e nem, necessariamente, a mais estratégica; 
- a segunda é a de que é falsa a oposição que muitos estabelecem entre os modelos de formação continuada, baseadas na racionalidade técnica ou nos saberes disciplinares e os que propõem desenvolvê-la em serviço, baseados na racionalidade prática ou no cotidiano da prática docente na escola;

- a terceira, é a de que a formação continuada em serviço se constitui em um momento insubstituível da formação dos professores,

- a quarta é a de que nenhuma formação continuada em serviço pode ser proposta desvinculada de uma forma mais geral de se conceber a prática educativa.

\section{BIBLIOGRAFIA}

Associação nacional Pela formação dos Professores em Educação - Anfope. Documento Final $X$ Encontro Nacional Brasília, 2000.

CANÁRIO, Rui. A escola: o lugar onde os professores aprendem. In: Anais do I Congresso Nacional de Supervisão na Formação. Portugal: Universidade de Aveiro, 1997.

A experiência portuguesa dos centros de formação das associações de escolas. In: Mari, Alda Junqueira (org.). Educação Continuada. Campinas: Edit. Papirus, p. 39-61, 2000

FRIGOTTO, Gaudêncio. A formação e profissionalização do educador frente aos novos desafios. In: VIII ENDIPE. Volume II - Florianópolis, 1996.

GARRIDO Selma. Qualificação do ensino público e formação de professores. Pesquisa CNPq 300051/90-5 (R/N). Educação (fev.) 2000.

NóVOA, António. Formação de professores e profissão docente. In: NÓVOA, António. Os professores e a sua formação. $2^{\mathrm{a}}$ ed., Lisboa: Publicações Dom Quixote Ltda., p. 15-33, $1995 \mathrm{a}$.

Professor se forma na escola. In: Nova Escola. Edição no 142 (maio). São Paulo: Abril Cultural, $2002 b$.

SCHÖN, Donald A. Educando o Profissional Reflexivo. Porto Alegre: Editora Artmed. 